\title{
Daily mortality changes in Taiwan in the 1970s: An examination of the relationship between temperature and mortality
}

\author{
Zhongwei Zhao, Yuan Zhu and Edward Jow-Ching Tu*
}

\section{Abstract}

Growing evidence indicates that world temperatures have increased in recent history, and that this trend is likely to continue in the future. The rise in global temperatures has been accompanied by an increase in extreme weather events, which often have devastating environmental, economic, demographic, and social effects. As concern about the impact of climate change has grown in recent years, there has been a considerable increase in the number of studies published on the effects of extreme temperatures. However, detailed, systematic, and historical investigations into the relationship between temperature and mortality relationship are still difficult to find. This study fills some of these gaps. By examining the impact of extreme temperatures on mortality in Taiwan in the 1970s, our aim is to answer the following questions: (1) Is a lower or a higher temperature recorded in winter or summer related to higher daily mortality? (2) Is mortality higher in particular years with extreme temperatures than it is in the corresponding periods of other years with normal temperatures? (3) Finally, if more extreme temperatures are indeed associated with higher mortality, what kinds of people tend to face higher mortality risks? This study shows that variations in daily mortality were related to changes in temperature in Taiwan over the study period. Cold temperatures in the winter, hot temperatures in the summer, and unusually cold or hot temperatures were all associated with higher mortality. In comparison with other times of the year, the proportions of people who died at old or very young ages were relatively high during cold periods. The proportions of deaths caused by cardiovascular diseases were also

\footnotetext{
* Zhongwei Zhao (corresponding author), Australian Demographic and Social Research Institute, Australian National University, 9 Fellows Road, Acton ACT 2601, Australia

Email: zhongwei.zhao@anu.edu.au

Yuan Zhu, Research School of Finance, Actuarial Studies \& Statistics, College of Business and Economics, Australian National University, Australia

Edward Jow-Ching Tu, Senior consultant, Asian Demographics and Retired Faculty of Hong Kong University of Sciences and Technology, Hong Kong
} 
relatively high, and these deaths contributed to the high mortality levels in winter time. Meanwhile, during the hot periods relatively high proportions of children and young people died of injuries or poisoning, and relatively high proportions of people died of respiratory diseases; both of these causes of death were closely related to mortality increases in the summer. In comparison with recent decades, however, these patterns were more observable in the 1970s, when the public health and the socioeconomic development levels in Taiwan were not as advanced as they are today.

\section{Introduction}

There is growing evidence that global temperatures have increased in recent years, and that this trend is likely to continue in the foreseeable future. The rise in global temperatures has been accompanied by an increase in extreme weather events, which often have devastating demographic, economic, environmental, and social effects (Hale et al. 2003; Goklany 2007; Deschenes and Moretti 2009; Hayhoe and Farley 2009; Steffen et al. 2013; Hajat et al. 2014). The heatwaves in India and Pakistan in May-June 2015 provided evidence that extreme temperatures coupled with poor public health systems and infrastructure can result in sharp increases in mortality. As concerns about the effects of climate change on the future of the planet and on humankind have grown, there has been a considerable increase in the number of studies published on the effects of extreme temperatures.

Previous studies have reported that there is a close association between temperature and mortality (Anderson and Bell 2009; Chung et al. 2009; Deschenes 2013). However, the relationship tends to be nonlinear. An unusually low or high temperature in winter or summer is often accompanied by higher mortality (Basu and Samet 2002; Chung et al. 2009; Guo et al. 2011). The extent to which this is the case varies across regions (Curriero et al. 2002; Deschenes 2013; McMichael et al. 2008). The optimal or threshold temperature (a temperature at which the risk of mortality reaches the lowest level) is usually related to the latitude and the temperature level of the area (Curriero et al. 2002). Studies have also suggested that the effects of hot temperatures on mortality are more immediate, while the effects of cold temperatures on mortality tend to accumulate over time, or become more observable after some delay (Deschenes 2013). In addition, Rocklov, Ebi, and Forsberg have found "the mortality impact of persistence of extreme high temperatures to increase proportionally to the length of the heat episode in addition to the effects of temperature based on the temperature-mortality relationship" (Rocklov et al. 2011). Notable variations have also been found when the association between temperature and mortality has been examined by causes of death. For example, links have been demonstrated between extreme temperatures and increases in cardiovascular and respiratory mortality, but links between temperature levels and cancer mortality have been more difficult to observe (Basu and Samet 2002; Astrom et al. 2011; Song et al. 2008). Similarly, some researchers have found that older people are most vulnerable to extreme temperatures (Basu and Samet 2002), while 
others have found associations between extreme temperatures and elevated mortality among children under four years old (Nakai et al. 1999; Vaneckova et al. 2008).

While great efforts have been made in recent years to study the impact of extreme temperatures on population health and mortality, detailed and systematic investigations into long-term changes in the temperature-mortality relationship are still difficult to find, especially in less developed countries. This study is designed to further improve our knowledge about these issues by examining the impact of extreme (both cold and hot) temperatures on mortality in Taiwan in the 1970s. We aim to answer the following research questions: (1) Is a lower or a higher temperature recorded in winter or summer related to higher daily mortality in the study population? (2) Is a more extreme (either cold or hot) temperature recorded in a particular year related to higher mortality than in the same period in other years? (3) If a more extreme temperature is indeed associated with higher mortality, which population sub-groups tend to have a higher mortality risk under the given temperature conditions?

When studying the association between temperature and population health and mortality, the concept of an 'extreme' or an 'unusual' temperature needs to be clearly defined. This is not, however, a straightforward task, because it often requires a careful consideration of the absolute level of temperature, the magnitude of temperature changes, and the duration of the cold or the hot temperature. These factors can have numerous combinations, and they interact with other meteorological or air quality factors. The effects of these factors, and of their combinations and interactions, also differ significantly across different geographic areas and climate zones (Wu et al. 2011). For these reasons, there is no standard or widely accepted definition of what constitutes an extreme temperature or an episode of extreme temperatures in the available studies.

The methods used to examine the effects of weather conditions on population health and mortality are also insufficiently developed. Most of the available studies have been conducted from one of the following perspectives. First, some studies have looked at cold or hot temperatures over a certain period, such as a year; and have investigated the health or mortality effects of these cold or hot temperatures. These studies have generally examined variations in temperatures and the associated differences in mortality levels, and have modelled the relationship between them (Medina-Ramón and Schwartz 2007; Zenobetti and Schwartz 2008; McMichael et al. 2008; Hajat et al. 2012; Hales 2012). Second, other studies have looked at whether extreme cold or hot temperatures during the same season or during the same period of different years led to excess mortality. Studies of this kind have, for example, investigated the health and mortality effects of heatwaves in Chicago in 1995, in Paris and other parts of Europe in 2003, or in other areas or at other times (Pirard et al. 2005; Kaiser et al. 2007; Tong et al. 2010; Tong et al. 2012). In this study, we analyse the effects of high or low temperatures from both methodological perspectives. Our definitions of extreme or unusual temperatures, measurements of mortality, and methods of analysis will be further discussed in related sections. 


\section{The study populations and climate in Taiwan}

In this study, we examine the relationship between temperature and mortality in northern and southern Taiwan over the period 1971-1980. The data used in this research have been provided by the Department of Statistics, the Ministry of Interior, the Central Weather Bureau, and the Environmental Protection Administration of Taiwan Executive Yuan, Taiwan; or were published on their websites. In this study, northern Taiwan includes Taipei, New Taipei (previously Taipei County), Taoyuan, and Keelung; and southern Taiwan includes Tainan, (previously Tainan City and Tainan County), and Kaohsiung (previously Kaohsiung City and Kaohsiung County). These categories are different from the official classifications, which also include some other areas. ${ }^{1}$ At the beginning of 1971, northern Taiwan had a total population of 4.06 million, while southern Taiwan had a total population of 3.07 million; these respective figures had risen to 5.88 and 3.75 million by the end of 1980, and to 9.10 million and 4.66 million by the end of 2014 (Department of Statistics, Ministry of Interior 2015). As is shown in Table 1, nearly 197,000 deaths were recorded in northern Taiwan and slightly more than 157,000 deaths were recorded in southern Taiwan over the study period. The table also provides other information about mortality and weather conditions for the study period.

Taiwan has a warm and humid climate. During the $20^{\text {th }}$ century, the average temperature in Taiwan was 23 degrees Celsius $\left({ }^{\circ} \mathrm{C}\right.$ ) (The Central Weather Bureau of Taiwan 2015). The weather conditions vary from the north to the south. Northern Taiwan has a subtropical climate with moderate temperatures, and rain is common in the region in the winter months. In southern Taiwan the temperatures are higher on average, and rain is less common than in the north.

The distance between Taipei (a major city in northern Taiwan) and Kaohsiung (a major city in southern Taiwan), where the two selected weather stations are located, is about 300 kilometres. For the study period, the mean daily temperature ranged from a minimum of $6.5^{\circ} \mathrm{C}$ to a maximum of $32.4^{\circ} \mathrm{C}$, and the average daily mean temperature was $22.8^{\circ} \mathrm{C}$ in the north. The average daily air pressure was $1012.8 \mathrm{hPa}$, and the average daily humidity was $76.9 \%$ rh. In the south, the mean daily temperature ranged from a minimum of $8.3^{\circ} \mathrm{C}$ to a maximum of $32.3^{\circ} \mathrm{C}$. The average daily mean temperature was $24.5^{\circ} \mathrm{C}$, or $1.7^{\circ} \mathrm{C}$ higher than in the north. In southern Taiwan, the average daily air pressure was $1011.1 \mathrm{hPa}$, and the average daily humidity $79.6 \%$ rh. The humidity level was slightly higher in the south than in the north.

1 According to the official classification used by the Executive Yuan, northern Taiwan consists of Taipei, New Taipei, Taoyuan, Keelung, Hsinchu City, Hsinchu County, and Yilan County; and southern Taiwan consists of Tainan, Kaohsiung, Chiayi City, Chiayi County, Pingtung County, and Penghu County. Because we have used only weather condition data collected from two weather stations, one in Taipei and the other in Kaohsiung, we have selected a smaller number of areas that are relatively close to these two major centres and that have relatively large population sizes. 
Table 1:

Weather conditions and mortality in the northern and southern Taiwan over the study period

\begin{tabular}{lcc}
\hline & Northern Taiwan & Southern Taiwan \\
\hline Max. daily mean temperature & $32.4^{\circ} \mathrm{C}$ & $32.3^{\circ} \mathrm{C}$ \\
Min. daily mean temperature & $6.5^{\circ} \mathrm{C}$ & $8.3^{\circ} \mathrm{C}$ \\
Ave. daily mean temperature & $22.8^{\circ} \mathrm{C}$ & $24.5^{\circ} \mathrm{C}$ \\
Max. daily mean air pressure & $1031.3 \mathrm{hPa}$ & $1027.1 \mathrm{hPa}$ \\
Min. daily mean air pressure & $977.5 \mathrm{hPa}$ & $981.4 \mathrm{hPa}$ \\
Ave. daily mean air pressure & $1012.8 \mathrm{hPa}$ & $1011.1 \mathrm{hPa}$ \\
Max. daily mean humidity & $98.0 \% \mathrm{rh}$ & $98.5 \% \mathrm{rh}$ \\
Min. daily mean humidity & $45.0 \% \mathrm{rh}$ & $43.0 \% \mathrm{rh}$ \\
Ave. daily mean humidity & $76.9 \% \mathrm{rh}$ & $79.6 \% \mathrm{rh}$ \\
Max. daily death count & 101 & 81 \\
Min. daily death count & 23 & 17 \\
Ave. daily death count & 53.9 & 43.0 \\
Number of deaths (1971-1980) & 196,848 & 157,094 \\
\hline
\end{tabular}

Note: Max., Min. and Ave. are abbreviations for maximum, minimum and average.

\section{Is a lower or a higher temperature recorded in winter or summer related to higher daily mortality?}

A total of 350,000 deaths were recorded in the two study areas from 1971 to 1980. During this period, daily death counts ranged from 23 to 101 in northern Taiwan and from 17 to 81 in southern Taiwan, as shown in Table 1. We start our investigation by examining the question of whether these very large variations were related to changes in temperature using the following analyses.

We first compute the daily mortality ratio, which is the daily death count to the average daily death count of the year; and use this ratio to indicate the relative level of daily mortality. We chose this indicator because it is less affected by the considerable changes in the number of deaths and in the level of mortality over the study period. All of the days in a year are then ranked by the mean daily temperature and are divided into 10 groups, with each group consisting of about the same number of days. The range of the daily average temperatures for the 10 groups is shown in Table 2. It is worth noting that there are some differences in the temperature ranges of the two study areas. Finally, we calculate the average daily mortality ratio for each of the 10 groups. The total number of days, the range of daily death counts, and the average daily mortality ratio for each group are also presented in Table 2.

An issue that needs to be taken into consideration in the study of the temperaturemortality relationship is the possibility that the effect of temperature on mortality is often delayed. Determining the length of such a lag effect is complicated, because it 


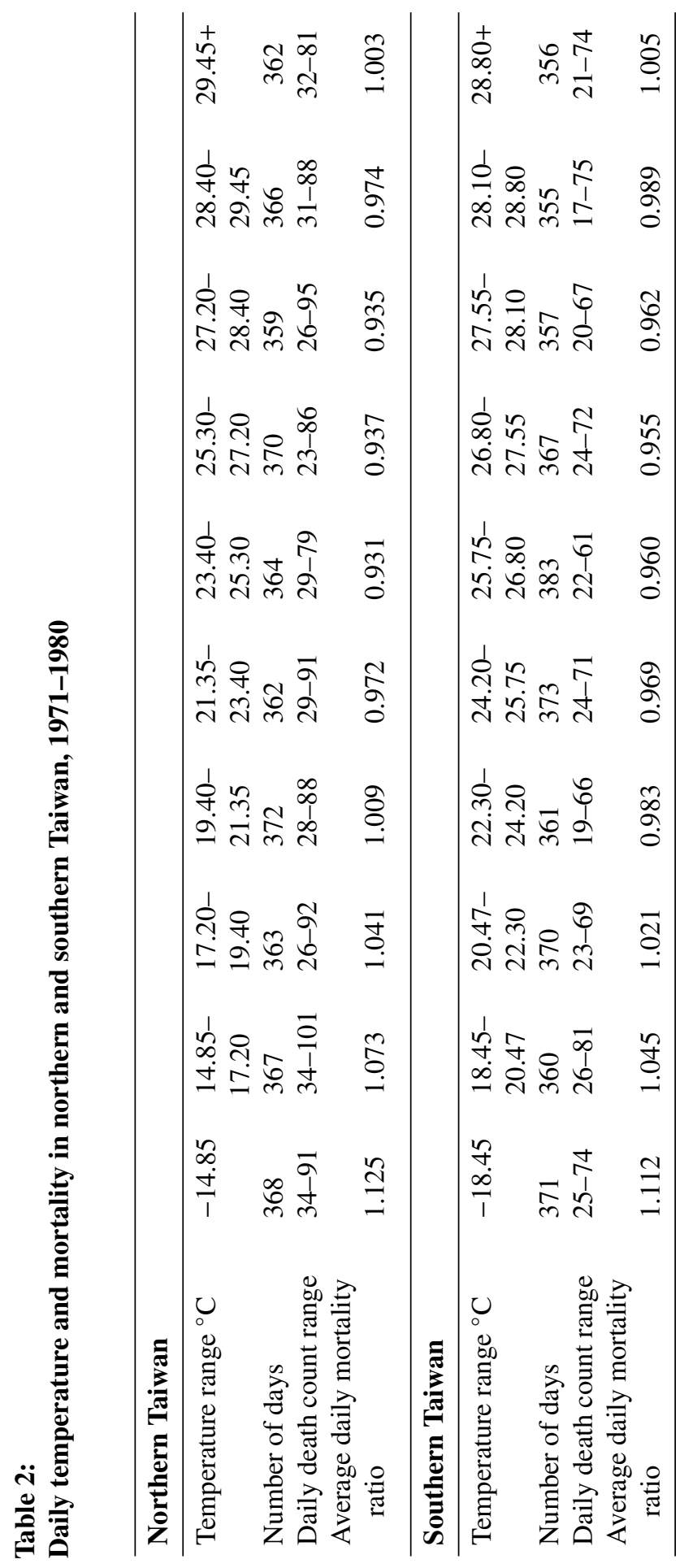


may be expected to vary depending on the cause of death, the health care facility, the geographic area, and other factors. Although these questions have been discussed in many papers, so far there is no conclusive answer about the length of lag that should be used in studies of this kind. We have examined the link between changes in daily mortality and the temperatures recorded in the preceding days, and found that in cold periods the correlation coefficient between the daily death count and the temperature recorded three days previously is slightly stronger, whereas in hot periods the correlation coefficient between daily mortality and the temperature recorded on the reference day or one day before the reference is slightly stronger. In the following analyses we use as a proxy the temperature recorded two days prior to death to capture the lag effect of temperature on mortality.

The results presented in Table 2 show a strong relationship between the daily temperature and the mortality level. Although winter in Taiwan is fairly mild, the number of deaths recorded in the coldest 10 per cent of days is about 1.13 times higher than the annual daily average in northern Taiwan. In southern Taiwan, the ratio is, at 1.11, slightly lower; which may be because the average daily temperature is a couple of degrees higher in the south than in the north. In both northern and southern Taiwan, daily mortality decreases when the average temperature increases, but this relationship begins to change when the temperature reaches $23.40-25.30^{\circ} \mathrm{C}$ in the north and $26.80-27.55^{\circ} \mathrm{C}$ in the south: at these thresholds, the average daily mortality ratio falls to its lowest level in each region, of 0.931 and 0.955 , respectively. After the 'optimal' temperature has been reached, changes in daily mortality generally show a positive relationship with temperature increases. For the group of days with the highest temperatures, the average daily mortality ratio is slightly higher than 1.00 in both northern and southern Taiwan.

The results from the relatively simple descriptive analysis are supported by multivariate analyses using a generalised additive model that accounts for the relevant environmental indicators, as specified below.

$$
E(Y \mid X, T)=a+S(T)+\sum_{n=1}^{4} S_{i}\left(X_{i}\right)
$$

Here $Y$ is predicted daily death count, $a$ is the intercept, $S$ and $S_{i}$ are smooth functions, $T$ is the time index, $X_{1}$ is lag 1 death, $X_{2}$ is lag2 temperature, $X_{3}$ is humidity, and $X_{4}$ is air pressure.

The results obtained from this analysis suggest that there is a non-linear relationship between temperature and mortality, as indicated by the graph in Figure 1. In the plot, $X$ is the temperature and the smooth function $S(X)$ shows the impact of the temperature on mortality, while holding the impact of other variables in the model constant. Here the impact is expressed in terms of the number of deviations from its mean, which is indicated by zero in the $\mathrm{Y}$ axis. The figure shows that when the temperature is low, the relationship between a change in the temperature and daily mortality is negative. But after the optimal temperature (approximately $26^{\circ} \mathrm{C}$ in both northern and southern Taiwan) has been reached, 
Figure 1:

Daily temperature and mortality in northern and southern Taiwan
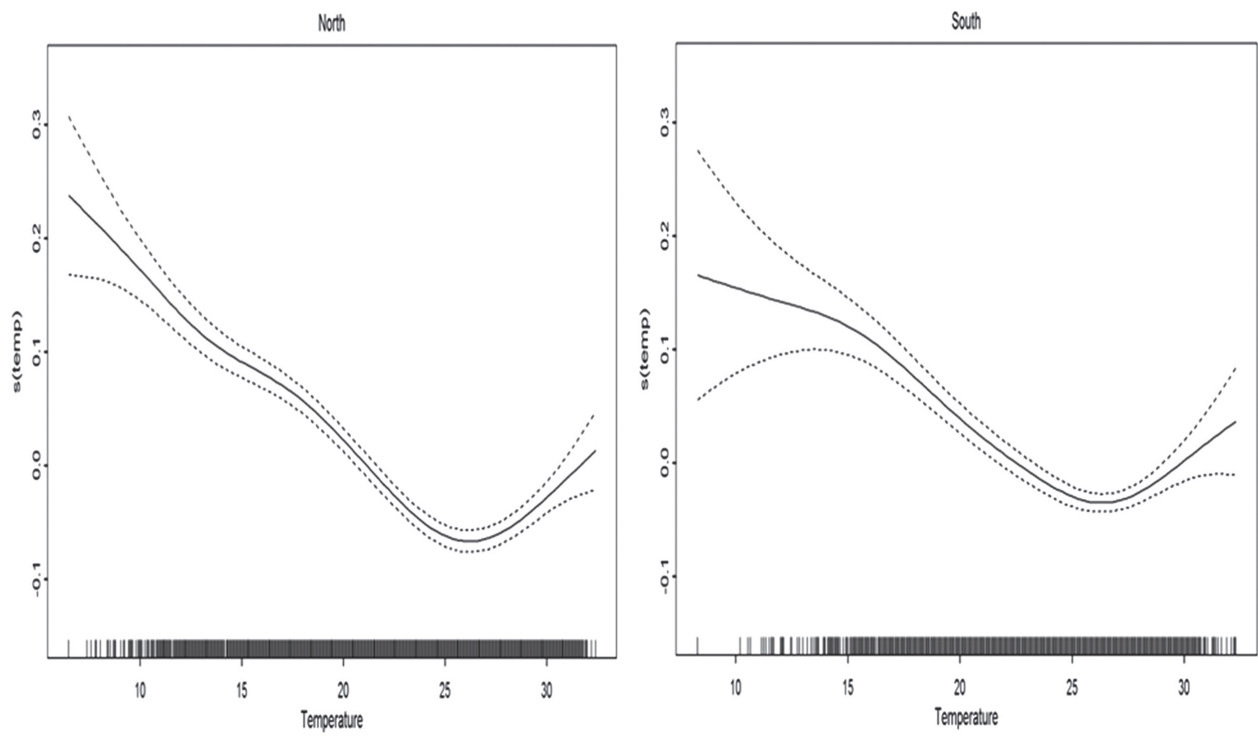

an increase in the temperature is positively related to an increase in mortality. The results also show that there are some differences in the temperature-mortality relationship in the two regions. There is a slightly larger increase in mortality in northern than in southern Taiwan when the temperature falls below $25^{\circ} \mathrm{C}$, which may be attributable to the slightly colder weather in the north. These results are consistent with the findings presented earlier.

\section{Is a more extreme temperature recorded in a particular year related to higher mortality?}

Temperatures recorded in the same period or season of different years can vary greatly. Are these variations also related to changes in the daily mortality level? For example, can periods with unusually cold or hot temperatures observed in a particular winter or summer (or other season) be shown to be associated with higher mortality than the corresponding periods or seasons of other years with normal temperatures?

To investigate these questions, we compared recorded temperatures for the same period across different years. To identify unusually cold or hot periods, both the temperature levels and the durations of these exceptionally high or low temperatures had to be taken into consideration. We first computed the average daily temperatures for every episode or period ranging from one to 20 days for the whole study period. 
For example, over the entire period of 3653 days there were 3652 episodes of two successive days. We computed the average daily temperature for each of these twoday episodes. We also did the same calculation for each episode of other specified numbers of days. This procedure enabled us to identify the hottest and the coldest periods with the specified duration over the entire study period. We then calculated the average daily mortality ratios for those coldest or hottest periods of one to 20 days, and noted the years in which these extreme temperature episodes occurred. Finally, we computed the average daily mortality ratios for the same periods of other years, and compared them with those recorded in the year in which the most extreme temperatures were observed.

Table 3 shows the coldest periods with durations of three, seven, 10, or 14 days; along with the dates when they occurred, the average daily mortality ratios for these periods, and the average daily mortality ratios for the same periods of other years. ${ }^{2}$ The results indicate that unusually cold temperatures were correlated with higher mortality in general, and especially during periods when the cold temperatures lasted for a longer time. For the coldest periods with seven, 10, or 14 days in northern Taiwan and the coldest periods with three, seven, 10, or 14 days in southern Taiwan the average daily mortality ratios varied from 1.18 to 1.29 in the years when these coldest spells were recorded. All of these ratios were markedly higher than the average daily mortality ratios in the other years, which were between 1.05 and 1.10. The only exception to this general pattern was found for a three-day episode of extreme cold observed in northern Taiwan from 25 to 27 February 1974: despite being very cold, the average daily mortality ratio during this episode was slightly lower than the ratio in other years.

Table 4 presents similar results showing the associations between hot or unusually hot temperatures and daily mortality. In northern Taiwan, the periods with the hottest three, seven, or 10 days had average daily temperatures of between $31.3^{\circ} \mathrm{C}$ and $32.0^{\circ} \mathrm{C}$. The average daily mortality ratios of these periods varied between 1.02 and 1.10, and were higher than the ratios for other years, which varied between 0.93 and 1.01. For the hottest 14-day episode recorded in August 1980, the average daily mortality ratio was 0.97 , or the same as the ratio observed in other years. In southern Taiwan, the hottest periods of seven, 10, or 14 days were all recorded in late June and early July 1980 , with average daily temperatures ranging from $31.3^{\circ} \mathrm{C}$ to $32.0^{\circ} \mathrm{C}$. The average daily mortality ratios for these episodes were 1.08 or 1.09 , and thus were higher than the ratios for the same periods in other years. However, for the hottest three-day period between 28 and 30 June 1980 the average daily mortality ratio was 0.95 , and was therefore lower than the ratios for the same periods of the other years. Compared with the ratios for the coldest periods, the average daily

2 As we mentioned in the last paragraph, we have computed average daily temperature and daily mortality ratios for every episode ranging from one to 20 days for the whole study period. The results are consistent with those shown in Tables 3 and 4, which (because of space restrictions) present only the results for episodes with durations of three, seven, 10, or 14 days. 
Table 3:

Average daily mortality ratios in periods with cold or unusually cold temperatures

\begin{tabular}{|c|c|c|c|c|}
\hline \multicolumn{5}{|l|}{ Northern Taiwan } \\
\hline Length of duration & 3 days & 7 days & 10 days & 14 days \\
\hline Coldest period & $25 / 2-27 / 2 / 1974$ & $27 / 2-4 / 3 / 1972$ & $25 / 1-3 / 2 / 1971$ & $25 / 1 /-7 / 2 / 1971$ \\
\hline Average mean temperature ${ }^{\circ} \mathrm{C}$ & 7.7 & 9.4 & 10.1 & 10.4 \\
\hline Average daily mortality ratio & 1.11 & 1.29 & 1.21 & 1.25 \\
\hline $\begin{array}{l}\text { Average daily mortality ratio } \\
\text { for other years }\end{array}$ & 1.14 & 1.06 & 1.07 & 1.10 \\
\hline \multicolumn{5}{|l|}{ Southern Taiwan } \\
\hline Length of duration & 3 days & 7 days & 10 days & 14 days \\
\hline Coldest period & $25 / 2-27 / 2 / 1974$ & $27 / 2-4 / 3 / 1972$ & $26 / 2-6 / 3 / 1972$ & $25 / 1-7 / 2 / 1971$ \\
\hline Average mean temperature ${ }^{\circ} \mathrm{C}$ & 10.5 & 12.7 & 14.3 & 14.7 \\
\hline Average daily mortality ratio & 1.18 & 1.22 & 1.24 & 1.22 \\
\hline $\begin{array}{l}\text { Average daily mortality ratio } \\
\text { for other years }\end{array}$ & 1.07 & 1.06 & 1.05 & 1.06 \\
\hline
\end{tabular}

mortality ratios for the hottest periods were generally lower. Thus, the temperaturemortality relationship seems to have been weaker and its patterns were less clear for hotter than for colder weather. This is likely due to the fact that even in summer, temperatures are not particularly high in Taiwan. When there is a heatwave, the temperatures rarely reach the levels that are routinely recorded in some other parts of the world.

We have also examined the distribution of average daily mortality ratios against the average daily temperatures recorded in the cold and hot periods specified in the two tables. The results provide further support for the conclusions reached above. There are, however, exceptions. For example, in northern Taiwan the average daily mortality ratio for the coldest three-day period was actually lower than the ratio for the corresponding periods of many other years. This may be because the daily mortality level is affected not only by the temperature level, but by many other factors as well.

\section{Which population groups are more vulnerable to the extreme temperature?}

Cold temperatures in winter and hot temperatures in summer-especially if they are unusually low or high-have been shown to be closely related to higher mortality. These findings are confirmed by the evidence presented in Tables 5 and 6 . In the two tables, we divide a year into three periods. The cold period consists of the days 
Table 4:

Average daily mortality ratios in periods with hot or unusually hot temperatures

\begin{tabular}{|c|c|c|c|c|}
\hline \multicolumn{5}{|l|}{ Northern Taiwan } \\
\hline Length of duration & 3 days & 7 days & 10 days & 14 days \\
\hline Hottest period & $3 / 9-5 / 9 / 1977$ & $21 / 7-27 / 7 / 1980$ & $12 / 7-21 / 7 / 1971$ & $20 / 7-2 / 8 / 1980$ \\
\hline Average mean temperature ${ }^{\circ} \mathrm{C}$ & 31.97 & 31.52 & 31.27 & 31.13 \\
\hline Average daily mortality ratio & 1.04 & 1.02 & 1.10 & 0.97 \\
\hline $\begin{array}{l}\text { Average daily mortality ratio } \\
\text { for other years }\end{array}$ & 0.93 & 0.96 & 1.01 & 0.97 \\
\hline \multicolumn{5}{|l|}{ Southern Taiwan } \\
\hline Length of duration & 3 days & 7 days & 10 days & 14 days \\
\hline Hottest period & $26 / 6-28 / 6 / 1980$ & $21 / 6-27 / 6 / 1980$ & $20 / 6-29 / 6 / 1980$ & $15 / 6-28 / 6 / 1980$ \\
\hline Average mean temperature ${ }^{\circ} \mathrm{C}$ & 32.02 & 31.39 & 31.35 & 31.11 \\
\hline Average daily mortality ratio & 0.95 & 1.08 & 1.09 & 1.08 \\
\hline $\begin{array}{l}\text { Average daily mortality ratio } \\
\text { for other years }\end{array}$ & 1.04 & 1.03 & 1.03 & 1.01 \\
\hline
\end{tabular}

from 16 December to 15 March. The hot period lasts from 16 June to 15 August. The remaining days of the year are grouped into a third, or 'other' period. This division is largely based on our examination of the mean temperatures recorded in these periods, their slight variations across different years, and their effectiveness in revealing the links between temperatures and variations in mortality among subpopulations.

Tables 5 and 6 show that the highest average daily death counts in a given year are in the cold period, followed by in the hot period. The lowest mortality levels are observed in the other period of the year. These patterns and the evidence presented in the preceding sections led us to ask the question of which groups are more vulnerable: i.e. which sub-populations are more likely to die during extreme temperature episodes? To answer this question, we calculated the percentage distributions of mortality by age groups and major causes of death for each of the three specified periods and for the study period as a whole; the results of these analyses are also presented in Tables 5 and 6.

The proportions of people who died at age 65 or above were higher in the cold period than in the other two periods of the year. In contrast, the proportions of people who died between ages one and 34 (as well as the proportion of infants who died before age one in the south) were higher in the hot period than in the other periods of the year. This pattern, which was observed for both northern and southern Taiwan, indicates that older people were more vulnerable to cold weather conditions, while younger people were more vulnerable to hot weather conditions. When the deaths were examined by causes of death, we found that the proportions of people who died due to cardiovascular diseases (CVD) were higher in the cold period than at 
Table 5:

Percentage distributions of deaths by different times of the year, northern Taiwan

\begin{tabular}{lcccc}
\hline & Cold period & Hot period & Other time & Average \\
\hline Average daily death count & 58.50 & 53.73 & 51.99 & 53.89 \\
By age groups (\%) & & & & \\
$\quad 0$ & 6.05 & 5.55 & 5.34 & 5.57 \\
$1-34$ & 12.61 & 18.39 & 15.32 & 15.10 \\
$35-64$ & 39.48 & 39.34 & 40.64 & 40.11 \\
65+ & 41.85 & 36.71 & 38.70 & 39.22 \\
By major causes of death $(\%)$ & & & & \\
Cancers & 16.44 & 18.47 & 18.69 & 18.05 \\
CVD & 32.20 & 25.77 & 29.14 & 29.40 \\
Respiratory diseases & 8.54 & 9.29 & 7.93 & 8.32 \\
Injuries and poisoning & 12.16 & 16.72 & 14.67 & 14.34 \\
Others & 30.66 & 29.74 & 29.57 & 29.89 \\
\hline
\end{tabular}

Table 6:

Percentage distributions of deaths by different times of the year, southern Taiwan

\begin{tabular}{lcccc}
\hline & Cold period & Hot period & Other time & Average \\
\hline Average daily death count & 45.64 & 43.20 & 41.84 & 43.00 \\
By age groups (\%) & & & & \\
$\quad 0$ & 6.29 & 7.29 & 6.49 & 6.57 \\
$1-34$ & 13.29 & 17.04 & 15.89 & 15.40 \\
35-64 & 36.04 & 36.77 & 37.17 & 36.80 \\
65+ & 44.39 & 38.90 & 40.45 & 41.22 \\
By major causes of death (\%) & & & & \\
Cancers & 13.25 & 15.03 & 14.92 & 14.50 \\
CVD & 30.30 & 25.22 & 27.21 & 27.69 \\
$\quad$ Respiratory diseases & 10.64 & 11.39 & 10.08 & 10.45 \\
Injuries and poisoning & 12.22 & 15.19 & 14.64 & 14.10 \\
$\quad$ Others & 33.59 & 33.17 & 33.15 & 33.27 \\
\hline
\end{tabular}

other times of the year. However, the percentages of people who died of injuries and poisoning and of respiratory diseases were higher in the hot period than in the other periods. These results reveal that compared with other times of the year, people were more likely to die of cardiovascular diseases in the cold period, and were at greater risk of dying from injury or poisoning in the hot period. Even after examining the 
Table 7:

Vulnerability indices by age groups and causes of death in cold and hot periods, 1971-1980

\begin{tabular}{llllll}
\hline & \multicolumn{2}{c}{ Cold period } & & \multicolumn{2}{c}{ Hot period } \\
\cline { 6 - 6 } \cline { 5 - 6 } & North & South & & North & South \\
\hline By age groups & & & & & \\
$\quad 0$ & 1.09 & 0.96 & & 1.00 & 1.11 \\
$1-34$ & 0.84 & 0.86 & & 1.22 & 1.11 \\
$35-64$ & 0.98 & 0.98 & & 0.98 & 1.00 \\
65+ & 1.07 & 1.08 & & 0.94 & 0.94 \\
By major causes of death & & & & & \\
$\quad$ Cancers & 0.91 & 0.91 & & 1.02 & 1.04 \\
CVD & 1.10 & 1.09 & & 0.88 & 0.91 \\
Respiratory diseases & 1.03 & 1.02 & & 1.12 & 1.09 \\
Injuries and poisoning & 0.85 & 0.87 & & 1.17 & 1.08 \\
$\quad$ Others & 1.03 & 1.01 & & 0.99 & 1.00 \\
\hline
\end{tabular}

mean daily death counts, we found that these conclusions applied to the populations living in both the north and the south.

To compare the vulnerability levels to extreme temperature conditions of the populations living in northern and southern Taiwan, we calculated a simple vulnerability index for the cold and hot periods: i.e. the ratio of the proportion of deaths of a specified age or causal group out of all deaths for the cold or hot period to the proportion of deaths of the same age or causal group for the whole study period. In general, a higher index value indicates a higher mortality risk (relative to the percentage of deaths among the same age or causal group in the total deaths of the study period). According to the vulnerability indices shown in Table 7, in the cold period the elevated mortality risks for people aged over 65 and for people with cardiovascular diseases were fairly similar in northern and southern Taiwan. In the hot period, the mortality risk among people aged 1-34, and the proportions of people who died of injury or poisoning or of respiratory diseases, were higher than in the other periods in both northern and southern Taiwan; although the gaps appear to have been greater in the north than in the south. In addition, in the cold period the mortality risk among infants under age one was higher than the average of the whole period in northern Taiwan, but not in southern Taiwan. The opposite was the case in the hot period. These observed differences should be further investigated in future studies.

To further examine the populations who were especially vulnerable in hot weather, we analysed the link between the relatively high proportion of people who died at ages 1-34 and the major causes of death. The results of the analysis provide 
further evidence in support of our previous conclusions. For example, we found that among people aged 1-34, injury or poisoning accounted for 52.6 per cent of deaths in the hot period, but just 45.6 per cent of deaths during the cold period. This gap is mainly attributable to the large number of deaths caused by drowning: in the hot period, the total number of drowning deaths was 2007, or more than three drowning deaths per day. These deaths accounted for 36.3 per cent of all injury or poisoning deaths among this age group. If the level of mortality caused by drowning in the hot period had been similar to the level in the cold period, then the total number of deaths due to injuries and poisoning that occurred in the hot period would have decreased by approximately 26 per cent. Injury and poisoning deaths would have accounted for 45.1 per cent of total deaths in the same age group, or slightly less than the 45.6 per cent of total deaths in the cold period.

We also examined the temperature-mortality relationship and levels of vulnerability to extreme temperature conditions in urban (cities) and rural (counties) areas, and in male and female populations. The vulnerability indices for cold and hot periods of the year are computed for cities and counties, and for males and females in northern and southern Taiwan; the results are presented in the four tables in the appendix of the paper. These results confirm the suggestions made above. In comparison with other times of the year or annual averages, the proportions of deaths among people aged 65 and over and of deaths caused by CVD were relatively high in the cold period. Meanwhile, the proportions of deaths among people aged 1-34 and of deaths caused by injury or poisoning or respiratory diseases were relatively high in the hot period. The variations in these patterns between urban and rural populations and between male and female populations were relatively small. However, in the hot period the vulnerability index for deaths caused by respiratory diseases was higher in the cities than in the counties in both northern and southern Taiwan. During the same period in both regions, the vulnerability index for deaths caused by respiratory diseases was higher among females than among males. It is beyond the scope of this paper to further analyse gender differentials in deaths due to this cause, but we will examine these differences in a future study.

\section{Concluding remarks}

This study has shown that variations in daily mortality were related to changes in temperature in both northern and southern Taiwan over the study period. Generally, cold temperatures in the winter, hot temperatures in the summer, and unusually cold or hot temperatures were all associated with higher mortality. However, daily mortality was generally higher in winter than summer.

Compared with other times of the year, the proportions of people who died at old and at very young ages were relatively high during the cold period. The proportions of deaths caused by CVD were also relatively high during this period, and contributed to the high mortality observed in winter time. People with these characteristics were thus more vulnerable to low temperatures. During the hot 
period, however, relatively high proportions of children and young people died of injury or poisoning. The proportions of deaths caused by respiratory diseases were also relatively high. These causes were closely related to the increase in mortality in summer time. People with these characteristics were more vulnerable during the hot season.

The analysis of the increase in summer mortality in Taiwan in the 1970s also makes clear that during this period the major reason for the rise in mortality in the hot season was not the increase in CVD mortality among elderly people, which might have been related to hot temperatures; but to other factors such as drowning among children and young adults, which may have been attributable to the poor or less effective safety management practices at the time. Since then, considerable efforts have been made to improve these practices. There has thus been a significant decline in deaths from drowning, and this decrease has contributed considerably to the reduction in summer mortality (Wang 1999 and 2007; Chen 2008).

The present paper has some limitations that should be acknowledged. While we focused on the relationship between temperature variability and mortality in Taiwan in the 1970s, we were unable to take into account the effects of other factors that may have contributed to mortality risk levels, such as air quality. We could not include these data because they did not become available until the mid1990s, and their exclusion may have had some effects on our results. Furthermore, the research findings reported in this paper offer insights into the temperaturemortality relationship and demographic differential vulnerability at a time when Taiwanese society was undergoing a demographic transition, and the country's level of socioeconomic development was less advanced than it is today. Thus, our observations of trends from more than three decades ago do not represent the temperature-mortality relationship patterns of today. Indeed, our investigations into this relationship have shown that it has not remained constant, but has undergone substantial changes since the 1980s. Big summer mortality peaks have largely disappeared in recent years. These changes are attributable to major changes in causes of death, improvements in health care and in living environments, and progress in safety management and disease prevention practices. (Zhao et al. 2015).

As we mentioned in the introduction of this paper, in recent years there has been a substantial increase in the discussion of the effects of global warming and associated extreme temperature events, such as heatwaves, on health and mortality. Some studies have also projected the extent of health or mortality effects into the future (Hajat et al. 2014). While such studies have greatly enriched our knowledge of related issues, it is notable that some of the reported results are based on observations made in one or two years, or in even shorter periods. It is also important to note that the temperature-mortality relationship has not been constant, but has undergone considerable changes. Furthermore, some temperature-related health and mortality risks can be prevented or considerably reduced. For example, in the summer of 2003 western European countries experienced a heatwave that resulted in more than 70,000 excess deaths (Robine et al. 2008). According to Fouillet and others (2008: 309), in France the high death toll was largely attributed to "an 
overall lack of reactivity by people (insufficient protective reflexes and help for the elderly), health professionals (poorly known diseases related to heat), the health system (difficulty perceiving the signals, lack of prevention recommendations) and the media (alarmist messages but no information on prevention)". In order to prevent this kind of heat-related disaster from happening again and to reduce the health effects of future heatwaves, a National Heat Wave Plan was set up by the Directorate General for Health. Thanks to the implementation of this plan and other related efforts, the impact on mortality of the 2006 heatwave was significantly lower (Fouillet et al. 2008).

Our study also highlights that it is crucial to consider demographic differentials in mortality risk from extreme temperature when developing disaster risk reduction strategies. We have shown that people of different age groups were exposed mortality risks differentially in hot and cold periods. Preventive policies that take into account the needs of specific sub-populations are essential for reducing premature deaths caused by extreme weather conditions and other environmental hazards.

\section{Acknowledgements}

We would like to thank the Hong Kong Government and the Academy of Social Sciences in Australia for having provided financial support for this study. We also want to thank the Department of Statistics, the Ministry of Interior, the Central Weather Bureau, and the Environmental Protection Administration of the Taiwanese Government for their support of our study.

\section{References}

Anderson, B. G. and M. L. Bell 2009. Weather-related mortality: How heat, cold, and heat waves affect mortality in the United States. Epidemiology 20(2): 205.

Åström, D. O., F. Bertil and R. Joacim 2011. Heat wave impact on morbidity and mortality in the elderly population: A review of recent studies. Maturitas 69(2): 99-105.

Basu, R. and J. M. Samet 2002. Relation between elevated ambient temperature and mortality: A review of the epidemiologic evidence. Epidemiologic Reviews 24(2): 190-202.

Chen, C. 2008. A study on the implementation of swimming instruction in elementary schools and students, satisfaction on swimming instruction in Kaohsiung City. National Taitung University: MA thesis.

Chung, J.-Y., Y. Honda, Y.-C. Hong, X.-C. Pan, Y.-L. Guo and H. Kim 2009. Ambient temperature and mortality: An international study in four capital cities of East Asia. Science of The Total Environment 408(2): 390-396.

Curriero, F. C., K. S. Heiner, J. M. Samet, S. L. Zeger, L. Strug and J. A. Patz 2002. Temperature and mortality in 11 Cities of the eastern United States. American Journal of Epidemiology 155(1): 80-87. 
Deschenes, O. 2013. Temperature, human health, and adaptation: A review of the empirical literature. Energy Economics 46(2014): 606-619.

Deschenes O. and E. Moretti 2009. Extreme weather events, mortality, and migration. The Review of Economics and Statistics 91(4): 659-681.

Fouillet, A., G. Rey, V. Wagner, K. Laaidi et al. 2008. Has the impact of heat waves on mortality changed in France since the European heat wave of summer 2003? A study of the 2006 heat wave. International Journal of Epidemiology 37(2): 309-31.

Goklany, I. M. 2007. Death and death rates due to extreme weather events. International Policy Press of the International Policy Network.

Guo, Y., A. G. Barnett, X. Pan, W. Yu and S. Tong 2011. The impact of temperature on mortality in Tianjin, China: A case-crossover design with a distributed lag non-linear model. Environmental Health Perspectives 119(12): 1719-25.

Hajat, S., S. Vardoulakis, C. Heaviside and B. Eggen 2012. Temperature effects of climate change on human health. In Health effects of climate change in the UK 2012: Current evidence, recommendations and research gaps, eds S. Vardoulakis and C. Heaviside, pp. 32-54. London: Health Protection Agency.

Hajat, S., S. Vardoulakis, C. Heaviside and B. Eggen 2014. Climate change effects on human health: Projections of temperature-related mortality for the UK during the 2020s, 2050s and 2080s. Journal of Epidemiology and Community Health 68: 641-48.

Hales, S., S. J. Edwards and R. S. Kovats 2003. Impacts on health of climate extremes. In Climate change and human health: Risks and responses, eds A. J. McMichael, D. H. Campbell-Lendrum, C. F. Corvalán, K. L. Ebi, A. Githeko, J. D. Scheraga and A. Woodward, pp. 79-102. Geneva: World Health Organization.

Hales, S., T. Blakely, R. H. Foster, M. G. Baker and P. Howden-Chapman 2012. Seasonal patterns of mortality in relation to social factors. Journal of Epidemiology and Community Health 66(4): 379-384.

Hayhoe, K. and A. Farley 2009. A Climate for changes: Global warming facts for faith based decision. New York: FaithWords.

Kaiser, R., A. Le Tert, J. Schwartz, C. Gotway, W. R. Daley and C. Rubin 2007. The effect of the 1995 heat wave in Chicago on all-cause and cause-specific mortality. American Journal of Public Health, Supplement 97: S158-S162.

McMichael, A. J., P. Wilkinson, R. S. Kovats, S. Pattenden, S. Hajat, B. Armstrong, N. Vajanapoom, E.M. Niciu, H. Mahomed, C. Kingkeow, M. Kosnik, M. S. O’Neill, I. Romieu, M. Ramirez-Aguilar, M. L. Barreto, N. Gouveia and B. Nikiforov 2008. International study of temperature, heat and urban mortality: The 'ISOTHURM' project. International Journal of Epidemiology 37(5): 1121-1131.

Medina-Ramón, M. and J. Schwartz 2007. Temperature, temperature extremes, and mortality: A study of acclimatisation and effect modification in 50 US cities. Occupational and Environmental Medicine 64(12): 827-833.

Ministry of the Interior (Department of Statistics), Taiwan, accessed in January 2015 at sowf.moi.gov.tw/stat/month/m1-09.xls.

Nakai, S., T. Itoh and T. Morimoto 1999. Deaths from heat-stroke in Japan: 1968-1994. International Journal of Biometeorology 43(3): 124-127. 
Pirard, P., S. Vandentorren, M. Pascal, K. Laaidi, A. Le Tetre, S. Cassadou and M. Ledrans 2005. Summary of the mortality impact assessment of the 2003 heat wave in France. Eurosurveillance 10: 153-6.

Robine, J.-M., S. L. K. Cheung, S. Le Roy, H. Van Oyen, C. Griffiths, J.-P. Michel and F. R. Herrmann 2008. Death toll exceeded 70,000 in Europe during the summer of 2003. Comptes Rendus Biologies, Dossier?: Nouveautés en cancérogenèse/New developments in carcinogenesis 331: 171-178.

Rocklöv, J., K. Ebi and B. Forsberg 2011. Mortality related to temperature and persistent extreme temperatures: A study of cause-specific and age-stratified mortality. Occupational and Environmental Medicine 68(7): 531-536.

Song, G., G. Chen, L. Jiang, Y. Zhang, N. Zhao, B. Chen and H. Kan 2008. Diurnal temperature range as a novel risk factor for COPD death. Respirology 13(7): 1066-1069.

Steffen, W., L. Hughes and D. Karoly 2013. The critical decade: Extreme weather. Commission Secretariat.

The Central Weather Bureau of Taiwan. Long-term changes in average temperature from data collected by 13 weather stations in Taiwan (Tabulated results), accessed in September 2015 at http://www.cwb.gov.tw/V7/climate/climate_info/monitoring/monitoring_7.html.

Tong, S., C. Ren and N. Becker 2010. Excess deaths during the 2004 heatwave in Brisbane, Australia. International Journal of Biometeorology 54(4): 393-400.

Tong, S., X. Wang and Y. Guo 2012. Assessing the short-term effects of heatwaves on mortality and morbidity in Brisbane, Australia: Comparison of case-crossover and time series analyses. PLoS One 7(5): e37500.

Wang, G. 1999. The analysis of drowning mortality trend in Taiwan from 1977 to 1997. Life Sciences 5: 91-111.

Wang, G. 2007. The prevention of drowning deaths and injuries, accessed in June 2015 at http://health99.hpa.gov.tw/Article/ArticleDetail.aspx?TopIcNo=32\&DS=1-Article.

Ye, X., R. Wolff, W. Yu, P. Vaneckova, X. Pan and S. Tong 2012. Ambient temperature and morbidity: A review of epidemiological evidence. Environmental Health Perspectives 120(1): 19-28.

Vanecko va, P., P. J. Beggs, R. J. de Dear and K. W. McCracken 2008. Effect of temperature on mortality during the six warmer months in Sydney, Australia, between 1993 and 2004. Environmental Research 108(3): 361-369.

Wu, P.-C., C.-Y. Lin, S.-C. Lung, H.-R. Guo, C.-H. Chou and H.-J. Su 2011. Cardiovascular mortality during heat and cold events: Determinants of regional vulnerability in Taiwan. Occupational and Environmental Medicine 68(7): 525-530.

Zenobetti, A. and J. Schwartz 2008. Temperature and mortality in nine US cities, Pier Interim Project Report.

Zhao, Z., Y. Zhu, J. Zhao and E. Tu 2015. The attenuation of summer mortality peaks in Taiwan, Paper presented in the 3rd Asian Population Association Conference, July 2015, Kuala Lumpur, Malaysia. 


\section{Appendix}

Table A.1:

Vulnerability indices by age groups and causes of death in cold and hot periods in northern Taiwan, 1971-1980

\begin{tabular}{llllll}
\hline & \multicolumn{2}{c}{ Cold period } & & \multicolumn{2}{c}{ Hot period } \\
\cline { 2 - 3 } \cline { 5 - 6 } & Cities & Counties & & Cities & Counties \\
\hline By age groups & & & & & \\
$\quad 0$ & 1.09 & 1.08 & & 0.99 & 1.00 \\
$1-34$ & 0.85 & 0.82 & & 1.19 & 1.20 \\
$35-64$ & 1.00 & 0.97 & & 0.97 & 0.99 \\
65+ & 1.04 & 1.09 & & 0.96 & 0.93 \\
By major causes of death & & & & & \\
$\quad$ Cancers & 0.91 & 0.91 & & 1.00 & 1.03 \\
CVD & 1.10 & 1.10 & & 0.91 & 0.87 \\
$\quad$ Respiratory diseases & 1.00 & 1.05 & & 1.17 & 1.11 \\
Injuries and poisoning & 0.84 & 0.85 & & 1.16 & 1.14 \\
$\quad$ Others & 1.03 & 1.02 & & 0.98 & 1.00 \\
\hline
\end{tabular}

Table A.2:

Vulnerability indices by age groups and causes of death in cold and hot periods in southern Taiwan, 1971-1980

\begin{tabular}{llllll}
\hline & \multicolumn{2}{c}{ Cold period } & & \multicolumn{2}{c}{ Hot period } \\
\cline { 2 - 3 } \cline { 5 - 6 } & Cities & Counties & & Cities & Counties \\
\hline By age groups & & & & & \\
$\quad 0$ & 0.95 & 0.96 & & 1.13 & 1.07 \\
$1-34$ & 0.86 & 0.86 & & 1.08 & 1.14 \\
$35-64$ & 1.00 & 0.97 & & 0.97 & 1.00 \\
65+ & 1.08 & 1.08 & & 0.98 & 0.94 \\
By major causes of death & & & & & \\
$\quad$ Cancers & 0.93 & 0.90 & & 1.01 & 1.06 \\
CVD & 1.08 & 1.10 & & 0.90 & 0.91 \\
Respiratory diseases & 0.99 & 1.03 & & 1.15 & 1.07 \\
Injuries and poisoning & 0.89 & 0.85 & & 1.04 & 1.09 \\
$\quad$ Others & 1.01 & 1.01 & & 1.03 & 0.99 \\
\hline
\end{tabular}


Table A.3:

Vulnerability indices by age groups and causes of death in cold and hot periods in northern Taiwan, 1971-1980

\begin{tabular}{llllll}
\hline & \multicolumn{2}{c}{ Cold period } & & \multicolumn{2}{c}{ Hot period } \\
\cline { 6 - 6 } \cline { 5 - 6 } & Males & Females & & Males & Females \\
\hline By age groups & & & & & \\
$\quad 0$ & 1.09 & 1.07 & & 0.95 & 1.06 \\
$1-34$ & 0.83 & 0.84 & & 1.23 & 1.14 \\
35-64 & 1.00 & 0.96 & & 0.98 & 0.98 \\
65+ & 1.07 & 1.06 & & 0.93 & 0.96 \\
By major causes of death & & & & & \\
$\quad$ Cancers & 0.92 & 0.90 & & 1.01 & 1.02 \\
CVD & 1.10 & 1.08 & & 0.87 & 0.91 \\
$\quad$ Respiratory diseases & 1.06 & 0.98 & & 1.08 & 1.21 \\
$\quad$ Injuries and poisoning & 0.84 & 0.89 & & 1.19 & 1.01 \\
$\quad$ Others & 1.04 & 1.01 & & 0.97 & 1.02 \\
\hline
\end{tabular}

Table A.4:

Vulnerability indices by age groups and causes of death in cold and hot periods in southern Taiwan, 1971-1980

\begin{tabular}{llllll}
\hline & \multicolumn{2}{c}{ Cold period } & & \multicolumn{2}{c}{ Hot period } \\
\cline { 6 - 6 } \cline { 5 - 6 } & Males & Females & & Males & Females \\
\hline By age groups & & & & & \\
$\quad 0$ & 0.96 & 0.95 & & 1.11 & 1.07 \\
$1-34$ & 0.85 & 0.88 & & 1.12 & 1.10 \\
35-64 & 1.00 & 0.95 & & 0.98 & 1.01 \\
65+ & 1.08 & 1.07 & & 0.95 & 0.95 \\
By major causes of death & & & & & \\
$\quad$ Cancers & 0.94 & 0.88 & & 1.05 & 1.03 \\
CVD & 1.10 & 1.09 & & 0.90 & 0.92 \\
$\quad$ Respiratory diseases & 1.03 & 1.00 & & 1.06 & 1.14 \\
$\quad$ Injuries and poisoning & 0.87 & 0.87 & & 1.07 & 1.06 \\
$\quad$ Others & 1.01 & 1.01 & & 1.00 & 1.00 \\
\hline
\end{tabular}

